\title{
La villa de Arándiga, del señorío de los Martínez de Luna, en el siglo XV: sus judíos*
}

\author{
Encarnación MARÍN PADILLA \\ CSIC, Madrid
}

\section{Ceyt (Cey, Çey)}

Varios judíos con este apellido residieron en Arándiga: Jehuda, mayor, sus hijos Abraham y Salamon, Mosse, hijo de este y nieto de Jehuda, otro Salamon, Hahim, Juce y Daniel.

De Jehuda consta que asistió a la reunión de la aljama el 30 de enero de 1444. En cuanto a los hijos de Jehuda, el 1 de diciembre de 1486, en Calatayud, Salamon vendió al converso bilbilitano Fernando López, menor, hijo del ciudadano Pedro López, mayor,

todo el aborton negro et blanquo que plegaran el y su hermano Brahem Cey, con que no pueda seyer mas el numero de lo blanquo que el de lo prito [sic] et si por ventura se plegara mas prito que blanquo que no pueda combrar mas blanquo que lo que avra plegado, a saber es, de mercaderes, etc.,

desde entonces hasta el siguiente día de Pascua Florida. Se pagaría la docena de «lo prieto» a nueve sueldos y de «lo blanquo» a tres sueldos seis dineros;

pagados e recibiendo los dichos abortones, buenos abortones fuera hopo de mala guisa, verendo, etc., nanyo de mala guisa et merino et revestido et roto, los quales dichos abortones ayan destar a vista et conoscimiento de Caçon Haym,

\footnotetext{
* Continuación de Sefarad 57 (1997) págs. 69-95 y 277-306, 58 (1998) págs. 271-
} 298 y 59 (1999) págs. 101-125. 
judío de la villa. En su nombre y en el de su hermano, Salamon también vendió al converso: «qualquiere salvagina, a saber es, rabosos» a once sueldos la docena; «hoyna» a dieciocho dineros la pieza; y «gineta et nutria aya destar a conoscimiento» de dicho Caçon; «buenas corambres de dar et recebir». Se estipuló que ni Salamon ni su hermano pudieran vender a persona alguna, ni

facer separacion ni apartamiento de algunas corambres, sino manifestarlas todas al dicho comprador et asin mesmo que sia tenido de fazer jurar al dicho su hermano de tener et conplir lo sobre dito, etc. Et bien teniendo cada huna de las dichas partes obliganse tener et complir.

A continuación, Salamon recibió en comanda de Fernando quinientos sueldos, de los que respondió con sus casas y su majuelo sito en «Baxerit» ${ }^{414}$. El mismo 1 de diciembre Jehuda Ceyt, mayor, padre de Salamon, vendió también al citado converso Fernando López todas las corambres «que plegaran»durante el tiempo dicho, a los mismos precios y con las señaladas condiciones; luego recibió en comanda del comprador sesenta y cuatro sueldos ${ }^{415}$. Es posible que el Salamon Ceyt que residió en Arándiga en 1486, en unas casas que lindaban con las de Alazar Serrano y con carrera pública, fuera el mismo Salamon Ceyt que en 1461 vivió en Calatayud. En ese caso, Salamon parece persona de espíritu inquieto, porque cuando el 19 de octubre de 1487, en esa ciudad, su hijo Mosse aparece como heredero de «todos los bienes, assin mobles como sedientes, que fueron» de su padre, se afirma que Salamon Ceyt fue «habitante en la villa de Cetina», en donde haría poco que había muerto.

En cuanto al ya citado Abraham; hijo de Jehuda y hermano de Salamon, se sabe que fue uno de los asistentes a las reuniones de la aljama del 8 de febrero de 1483 y del siguiente 7 de abril en la sinagoga.

Por lo que se refiere a Mosse Ceyt, el citado día 19 de octubre de 1487, en Calatayud y como heredero de Salamon, vendió al judío bilbilitano Mosse Lapapa, por trescientos sueldos, los seiscientos sueldos que debían en comanda ${ }^{416}$ el clérigo

${ }^{414}$ Lindaba con la carrera y con pieza del mismo Salamon Ceyt.

415 C.APN., Forcén López, 1486, fols. 199-201.

416 Hecha el 1 de febrero de 1474 , en dicha ciudad. 
vicario del barrio de Tores, mosén Sancho Torres, y su hermano Sancho Torres, vecino de la aldea de Villalba ${ }^{417}$. No fue mucho el tiempo que Mosse sobrevivió a su padre. El 2 de agosto de 1490, en Arándiga, se encontraba Abraham Ceyt «dentro en un palacio stant en las casas de Salamon Ceyt ${ }^{418}$, el qual palacio esta al cabo de la dicha casa» ${ }^{419}$. Allí Abraham "descubrio, si quiere, levanto un linçuelo de un lecho que stant dentro del dicho palacio en donde stant muerto el dicho Mose Ceyt», ante el notario y testigos, quienes «conocimos ser aquel muerto el dicho Mose Ceyt por quanto lo conociamos muy bien et stava muerto en el dicho lecho». Entonces Abraham dijo que «en testimonio de verdat ... requiria a mi nótario faziesse acto publico», para en el futuro probar la muerte de Mosse ${ }^{420}$. El hecho de que no fuera Salamon quien descubrió el rostro de su difunto hijo, induce a pensar que, efectivamente, había fallecido.

En cuanto al otro Salamon Ceyt, consta que asistió a la reunión de la aljama que tuvo lugar el 5 de junio de 1490 , en Arándiga.

Por lo que se refiere a Hahim Ceyt sólo se sabe que fue uno de los asistentes a la reunión de la aljama del 8 de febrero de 1483.

El otro componente de la familia, Juce Ceyt, actuó como testigo instrumental en la reunión de la aljama del $\mathbf{3 0}$ de enero de 1444 , en la villa.

Por lo que se refiere a Daniel Ceyt, asistió a las reuniones de la aljama del 7 de abril de 1483 en la sinagoga, del 5 de junio de $1490 \mathrm{y}$, como adelantado, a la del siguiente 17 de agosto. Daniel había dado a medias dos vacas suyas al moro vecino de Chodes Ali el Donyali; como el acuerdo fue por cinco años, en 1492 eran «agora cinco baquas». Días antes del plazo fijado para que los judíos abandonaran el reino de Aragón, concretamente el 22 de julio de dicho año, en La Almunia de Doña Godina y mientras preparaba su marcha, Daniel vendió el de-

417 C.APN., Juan Remón, 1487, fols. 192v-193.

418 Aparece como residente en la villa y no se dice que hubiera muerto.

419 Se dice aquí que lindaban con carrera pública y «con calliço por donde tienen su entrada».

${ }^{420}$ L.A.APN., Miguel Contín, 1490, fol. 56v. 
recho que sobre ellas tenía al labrador vecino de Arándiga Pedro Marquesa, por cien sueldos ${ }^{421}$. Seis días después, Daniel se encontraba en Tortosa.

\section{Cogulla (Coculla, Engulla)}

Un único judío con este apellido residió en Arándiga: el tejedor Juce, que asistió a las reuniones de la aljama del 30 de enero de 1444 y de octubre de 1475.

El 13 de agosto de 1489, en Arándiga, Juce compareció ante el tribunal del Santo Oficio de la Inquisición para manifestar que oyó decir a Mosse Xalon que él y su hermano converso Juan acordaron pasar a Nápoles, donde murió su hermano Jehuda, y aunque luego él no fue, lo hizo Juan que dio carta de «quitacion» y licencia a la esposa judía de su difunto hermano para que se casara, porque ya tenían cambiados anillos, a modo judaico ${ }^{422}$. El 17 de agosto de 1490, Juce fue uno de los asistentes a la reunión de la aljama.

\section{Cohen}

Varios judíos con este apellido residieron en Arándiga: Abraham, Mosse, Sento, su hijo Juceu, y Simuel.

Abraham actuó como adelantado de la aljama, en solitario, en la reunión de esta que tuvo lugar el 19 de julio de 1428.

Mosse, que asistió a la reunión de la aljama del 25 de abril de 1455, se encontraba en Tortosa el 28 de julio de 1492, para salir con los judíos expulsados del reino.

En cuanto a Sento, que vivió en unas casas de Arándiga que lindaban con las de Acach Serrano ${ }^{423}$, la primera noticia documental que a él alude está fechada en 1451, cuando tuvo arrendadas las «rendas, fruytos e emolumentos de los lugares» de La Almunia de Doña Godina, Alpartir y Cabañas, pertenecientes al castellán de Amposta, junto con los labradores cristianos Juan de Calcena, Ximeno Abás, Blas de Ervás y Ximeno Martínez, los judíos vecinos de Arándiga Juce Ucles y Cadoch Al-

${ }^{421}$ Dicho notario, 1492, fol. $84 \mathrm{v}$.

422 Z.AAT, leg. $18, n^{\circ} 7$, fol. 2.

${ }^{423}$ C.APN., Leonardo de Santa Fe, 1473, fol. 100v. 
balit, los judíos de Illueca Bienbenist Abenpessat y Nahamias Cogulla, el alamín de Chodes Yuce el Alamin y el alamín de Gotor Brahem Canyazet, que habitaba en Calatayud ${ }^{424}$. El 31 de agosto de dicho año, en La Almunia y sin revocar procuradores, dichos arrendadores hicieron procurador suyo al alamín de Morata don Ali el Ferrero, que estaba presente y aceptó, para dar, haber, recibir y «collir» todas las rentas, frutos, treudos y emolumentos de dichos lugares, para «poner» una y muchas «collidas» en aquellos y hacer todos los actos que los arrendadores acostumbran, para hacer albaranes de «paga y recepta», para pleitos, demandas y cuestiones, para jurar y con poder de sustitución ${ }^{425}$. El 29 de junio de 1483, Sento se encontraba en La Almunia de Doña Godina para otorgar dos instrumentos públicos. En uno, dio en comanda al labrador vecino de Ricla Domingo López doscientos diez sueldos ${ }^{426}$. En el otro, compró al también labrador vecino de Ricla Martín Millán sus casas, sitas «dentro del muro» del lugar ${ }^{427}$; Sento pagó por ellas doscientos sueldos ${ }^{428}$, pero Martín podía volverlas a comprar por la misma cantidad en el plazo de diez años ${ }^{429}$. Sento había asistido ese mismo año a la reunión de la aljama del 8 de febrero y del siguiente 7 de abril en la sinagoga. Han de transcurrir más de cinco años para que se vuelva a tener noticia de Sento. El 12 de agosto de 1488, en Arándiga, este compareció ante el tribunal del Santo Oficio para acusar al tamborino de la villa Francisco de Tarazona de haber

${ }^{424}$ Todos residentes en lugares que pertenecían al noble don Jaime Martínez de Luna; según constaba en carta pública de arrendación hecha en La Almunia de Doña Godina por Gil Martínez, regidor y procurador del dicho castellán, el 30 de agosto de 1451, ante el notario Juan de Samper.

425 Todos obligaron sus personas y bienes, muebles e inmuebles (L.A.APN., Pascual Contín, 1451, fols. 96-96v). El 4 de julio de 1453, en Zaragoza, dicho procurador Ali el Ferrero nombró procurador de sus principales al notario causídico Juan Valero, vecino de Zaragoza, que no estaba presente, para pleitos y con poder de jurar y de sustitución (dicho notario, 1453, fol. 62v).

${ }^{426}$ Respondió de la cantidad recibida con un par de novillos, «uno bragado el otro de pelo royo»; especificó, por juramento, la forma de pago (L.A.APN., Miguel Contín, 1483, fols. 35-35v).

427 Lindaban con otras suyas, con las del moro Yuce Cavales y con carrera pública.

${ }^{428} \mathrm{De}$ los que respondió el labrador con otras casas suyas contiguas, que lindaban con las del moro Brahem de Farax.

${ }^{429}$ Dicho notario y año, fols. $35 \mathrm{v}-36$. 
comido carne y viandas judaicas, cuando asistió a las bodas de unas hijas de Jehuda Çarfati, para «tanyer» ${ }^{430}$. Dos años después, Sento asistió a la reunión de la aljama del 5 de junio de 1490 y, como adelantado, a la del siguiente 17 de agosto. E1 13 de octubre de dicho año, también en Arándiga, Sento dio en comanda al moro de Chodes Yuce el Dunyal trescientos sesenta sueldos y tres cahíces de trigo ${ }^{431}$. En la «contra carta» que Sento le otorgó, además de las condiciones de pago, se especificó que, si no pagaba alguna de las tandas, podría ser «capcionado e exsecutado» por lo no pagado; si lo hacía, le otorgaría el correspondiente albarán y le devolvería dos contratos: uno, en el que Yuce estaba obligado al vecino de Arándiga Pedro Valero, "por mi» Sento, en ciento veinte sueldos, y otro, en el que estaba obligado a él, Sento, en doscientos ${ }^{432}$. El 7 de abril de 1491, de nuevo en La Almunia de Doña Godina, Sento otorgó tres instrumentos públicos: dio una comanda de trescientos sueldos al vecino de allí Miguel Gastón ${ }^{433}$; otra, a la viuda Martina Catalán de doscientos sueldos, tres cahíces tres fanegas de trigo y tres cahíces tres fanegas de cebada ${ }^{434}$; y recibió de dichos Martín y Martina, respectivamente, doscientos sueldos y once cahíces siete fanegas de trigo ${ }^{435}$, y doscientos veinticuatro sueldos, tres cahíces tres fanegas de trigo y tres cahíces tres fanegas de cebada ${ }^{436}$; otorgó los correspondientes albaranes ${ }^{437}$. Meses después de estas comparecencias, concretamente el 29 de octubre de 1491, en Arándiga y ante el notario Pedro Ximénez Pardo que vivía en Villanueva, Sento hizo testamento en el que nombró tutor de su hijo Juceu a su convecino Abraham Çarfati.

\footnotetext{
${ }^{430}$ Z.AAT., leg. $18, n^{\circ} 6$, fols. $2-2 \mathrm{v}$.

431 Medida de Zaragoza; obligó su persona y bienes.

${ }^{432}$ Sento obligó sus bienes a cumplirlo (L.A.APN., Miguel Contín, 1490, fols. $68 \mathrm{v}-69 \mathrm{v})$.

${ }^{433}$ De los que respondió con su persona y bienes; nombró procuradores. En las condiciones de pago que se especificaron, se hizo constar que, si dejaba de pagar alguna tanda, por ello sería «exsecutado et bexado" hasta que lo hiciera. ${ }^{434}$ Medida de Zaragoza; obligó sus bienes. En las condiciones de pago que se especificaron, se puntualizó: «et que podays ser executada et vexada por la tanda que havreys cessado de pagar».

${ }^{435}$ Que le debía en comanda hecha allí, el 10 de noviembre de 1479.

436 Que le debía en comanda hecha allí, el 3 de marzo de 1482.

${ }^{437}$ L.A.APN., Miguel Contín, 1491, fols. 38-40.
} 
Cuando faltaban sólo unos días del plazo fijado para que los judíos abandonaran el reino de Aragón, el 22 de julio de 1492, en La Almunia de Doña Godina y como procurador y tutor testamentario del huérfano Juceu Cohen, Abraham Çarfati recibió de Miguel Gastón cien de los trescientos sueldos que debía en comanda a Sento, y otorgó albarán ${ }^{438}$.

Por lo que se refiere a Simuel Cohen, sólo se tiene noticia de las entregas en sueldos y en grano que dio en 1476: Martín Romero ${ }^{439}$ juró pagarle sesenta sueldos anuales hasta abonar la comanda y censal que su madre y Miguelico le debían; Antón Sadornil, mayor, y Antón Sadornil, menor ${ }^{440}$, recibièron en comanda ciento setenta sueldos, el 29 de noviembre; y los vecinos de El Frasno Domingo Roy y Juan Zuera, tres cahíces tres fanegas de cierto grano, que no se especificó, el 18 de diciembre ${ }^{441}$. Simuel asistió a la reunión de la aljama del 8 de febrero de 1483 y, como adelantado, a la del siguiente 7 de abril.

Chopi (Chap, Chapi, Copi y Copin)

Dos judíos con este apellido residieron en Arándiga: Abraham y Leon.

Abraham asistió a la reunión de la aljama del 30 de enero de 1444, de octubre de 1475 como adelantado y del 17 de agosto de 1490.

En cuanto a Leon, sólo nos consta que tuvo una viña en el término de Castejón, que lindaba con la de Mosse Arruet que, a su vez, lo hacía con la de Juan Royo y con carrera pública ${ }^{442}$.

Eli (Ely)

Tres judíos con este apellido residieron en Arándiga: Salamon, su hijo Caçon y Jaco.

El zapatero Salamon Eli, casado con «Rehuqua», vivió en Épila y en La Almunia de Doña Godina, villa en la que per-

\footnotetext{
${ }^{438}$ Dicho notario, 1492 , fols. $84 \mathrm{v}-85$.

439 No se especificó su residencia.

${ }^{440}$ No se especificó su residencia.

${ }^{441}$ Respondieron con inmuebles (C.APN., Juan Mainar, 1476, fols. 106v-107).

${ }^{442}$ L.A.APN., Miguel Contín, 1491, fols. 98-99.
} 
maneció su hijo Juce, pero que el matrimonio abandonó con su otro hijo Caçon para residir, al menos desde 1446, en la de Arándiga, del señorío de los Martínez de Luna. El 25 de abril de dicho año, Salamon recibió en comanda del también zapatero bilbilitano Luis de Heredia ciento cuarenta y cinco sueldos ${ }^{443}$. Meses después en Épila, el 1 de octubre, Salamon vendió sus casás del barrio de las Eras de esta villa ${ }^{444}$ al epilense Martín de Riello, por veinte sueldos de precio que otorgó haber recibido con «el aliara ensenble, franquas e quitas sines de ninguno cargo excepto la peyta hordinaria del senyor» ${ }^{445}$. El cambio de residencia a Arándiga, donde vivieron en unas casas que lindaban con las de Pedro Meollo, con las del difunto $\mathrm{Ca}$ doch Albalit y con carrera pública, no parece que mejorara la situación económica de Salamon y de su hijo Caçon, también zapatero. El 26 de enero de 1448, en La Almunia de Doña Godina, Salamon y Caçon recibieron en comanda del notario vecino de allí Miguel de Longares cien sueldos ${ }^{446}$. El 1 de agosto de 1451, de nuevo en Épila, Salamon, su mujer y su hijo Caçon manifestaron que pagarían al judío trapero de la villa de Tauste Hahim Abenforna cincuenta florines de oro, desde entonces hasta el siguiente día de Santa María de Septiembre; de dicha cantidad respondieron con sus casas de Arándiga ${ }^{447}$. Transcurridos dos años, parece que los medios de fortuna de Salamon habían aumentado. El 13 de agosto de 1453, pagó al zaragozano Guillén de Gálvez, mayor, los trescientos sueldos que él y el judío epilense Hahim Gaddax debían en comanda ${ }^{448}$. El 10 de enero de 1460, en Épila, Salamon Eli vendió al escudero epilense Ochona de Ortubia una comanda de tres-

${ }^{443}$ C.APN., Antón Martínez de la Justicia, 1446, fols. 135v-136.

${ }_{444}$ Lindaban con las de Pedro Riello, padre de Martín, y con carreras por dos partes.

445 Entonces don Lope Ximénez de Urrea (L.A.APN., Martín de Marín, 1446, fols. $78 \mathrm{v}$ y $79 \mathrm{v}$ ).

446 Obligaron sus personas y bienes, que no se especificaron, y nombraron procuradores (L.A.APN., Pascual Contín, 1448, fols. 16v-17).

${ }_{447} \mathrm{Y}$ «prendemos quinyan de falda de buen panyo de Jaco Gotina, jodio testimonio ... de tener e complir todo lo sobre dito e de non firmar de dreyto» (L.A.APN., Martín de Marín, 1451, fols. 112v-113).

448 Hecha el 19 de agosto de 1436, en Épila. La participación de dicha carta de comanda en la que los dos judíos estaban obligados a él y a Pedro Salvador, hijo del difunto ganadero zaragozano Berenguer Salvador, la compró Guillén el 29 de noviembre de 1452, en Zaragoza, a Bartolomé y Martín Salvador, hermanos de Pedro y herederos universales suyos (dicho notario, 1453 , fol. $50 \mathrm{v}$ ). 
cientos sueldos ${ }^{449}$. Dicha comanda no perteneció de forma pública a Salamon hasta el siguiente 16 de febrero, cuando compró a su convecino Blas de Ervás los trescientos florines de oro que el judío zaragozano Jaco Eli le debía en comanda ${ }^{450}$; el precio, la cantidad debida, los recibió con el alifara ${ }^{451}$. Un mes después en Épila, el 17 de marzo, el judío zaragozano Juce Eli, mayor, heredero universal de su padre Jaco Eli, pagó al escudero Ochona los trescientos sueldos ${ }^{452}$. El siguiente 1 de septiembre en Calatayud, Salamon y su hijo Caçon pagaron al converso Juan López de Villanova, hijo del difunto mercader bilbilitano don Fernando López de Villanova, los cien sueldos que debían en comanda ${ }^{453}$ y que habían jurado págarle en varias tandas ${ }^{454}$.

Por lo que se refiere al zapatero Caçon Eli, además de los instrumentos públicos en los que compareció con su padre, actuó como testigo instrumental en La Almunia de Doña Godina ${ }^{455}$ : el 20 de febrero de 1448, en la firma de Ezter Arrueti, menor, hija del judío albardero de allí Juce Arrueti, con su convecino Juce Frances, por dos años ${ }^{456}$; y el 11 de agosto de $1451{ }^{457}$. Caçon, que asistió a la reunión de la aljama el 25 de abril de 1455, en Arándiga, vivió en unas casas de la villa que lindaban con las de Pedro Aviñón y con las de Cadoch Albalit y fue dueño de una viña en el término de Castejón ${ }^{458}$. Con ambos inmuebles respondió Caçon de los ciento veinte sueldos

\footnotetext{
${ }^{449}$ Que compró el 10 de septiembre de 1446, en Arándiga.

${ }^{450}$ Hecha el 10 de septiembre de 1446, en Arándiga.

451 Dicho notario, 1460 , fols. $15 \mathrm{v}-16$.

${ }^{452}$ Dicho notario y año, fol. 24.

453 Hecha el 10 de marzo de 1458, en Calatayud.

454 C.APN., Leonardo de Santa Fe, 1460, fols. 31v-32.

455 Residente en esta villa, escribe el notario.

${ }^{456}$ L.A.APN., Pascual Contín, 1448, fol. 30v.

457 Como residente en Arándiga, en la comanda de doscientos sueldos que dio, el 11 de agosto de 1451, el judío de La Almunia de Doña Godina don Jehuda Albala a los labradores vecinos de Arándiga Beltrán de Añón y su «entenado» Pedro Serrano. Respondieron de la cantidad recibida: Beltrán con sus casas que lindaban con las de Juan Calvo, con carrera pública y «con las aras", y con una pieza en el término de la Foya, que lindaba con la de Juan de Bazán y con la de Juan de Codos; y Pedro con sus casas que lindaban con carrera pública y con corral de Francisca Arella, y con una viña en el término de Castejón, que lindaba con la de Juan de Calcena y con la de Jaco Cariello (dicho notario, 1451 , fol. $87 \mathrm{v}$ ).

${ }^{458}$ Lindaba con las de Juan Alavés y con campo de Juan Cavero.
} 
que, el 16 de abril de 1455, en Calatayud, recibió en comanda del mercader converso bilbilitano Jaime Álvarez; este prometió que, si la pagaba en agosto y las «espensas» que hiciera, otorgaría «difinimiento» general a él y a su padre de todo lo que le debían hasta entonces; así lo hizo el siguiente 17 de septiembre, cuando le pagaron ${ }^{459}$. Un año después, el 29 de abril de 1456 , en Épila, cuando su hermano Juce había cambiado su residencia a esta villa, Caçon reconoció tener en «comanda, si quiere, fiel deposito» del judío epilense Mosse Sumiel doscientos sueldos; se especificó que la comanda «se ys feita a eviccion, si quiere, salvedat» de su hermano Juce, que «ys obligado por el», en Calatayud, al citado converso bilbilitano Fernando López de Villanova; y que cuando a este se le pagaran ciento setenta sueldos, la carta de comanda debida a Mosse se tendría por no hecha ${ }^{460}$. El 1 de septiembre de 1460 , Caçon y su padre pagaban cien sueldos al converso Juan López de Villanova, hijo de Fernando, como se ha visto. Han de transcurrir unos ocho años para que se vuelva a tener noticia de Caçon, que se encontraba en Épila, ignoramos por qué. El viernes 26 de agosto de 1468 , dentro de las casas del merino de esta villa don Juan Sánchez de Sarriá, comparecieron Caçon Eli y su convecino Alazar Serrano. «Con grandes vozes de apellido e aquellas continuando ante la presencia del dito merino contra» el vecino de la villa Abraham Carillo, diciendo:

\begin{abstract}
Abi, bi, vi, fuerça, como nosotros, merino senyor, el present dia stamos a la puerta de la posada de Maria de la Nodriza con intencion de hir nuestro camino ${ }^{461}$... ius proteccion salvaguarda del senyor Rey e del senyor don Lop Ximenez d'Urrea, visorey de Sicilia e de su procurador e de sus officiales, no faziendo mal a ninguno ni pensant que otri ninguno lo fizies a nosotros, stando el dito Abraham Cariello movido de spiritu maligno con el spada bantada e aya sciertos colpes con aquella al dito Elazar e a mi por meter en medio e si no fues stado por algunas buenas personas que alli se trobaron que se metieron nole en medio, no lo agradecemos de la vida; por do, merino senyor, vos requerimos con tanta instancia quanto dezir se pueda.. .462 .
\end{abstract}

\footnotetext{
${ }^{459}$ C.APN., Jaime García, 1455, fols. 129v y 274.

${ }^{460}$ L.A.APN., Martín de Marín, 1456, fol. 28v.

${ }^{461}$ Hay un espacio en blanco como de dos o tres palabras.

${ }^{462}$ Dicho notario, 1468, fol. 27.
} 
El instrumento público no terminó de redactarse, pero el requerimiento sería una petición de prisión para el atacante y exigencia de daños y perjuicios; el merino cumpliría con su obligación, una vez informado del motivo que movió a Abraham a empuñar la espada contra Caçon y Alazar. Se ignora cómo terminó la cuestión, si Abraham pagó las curas de las heridas que causó, y quién fue el médico que atendió a los dos judíos de Arándiga que en mal momento viajaron a Épila. La última noticia documental que alude a Caçon, después de saber que fue uno de los asistentes a las reuniones de la aljama del 8 de febrero de 1483 y a la del siguiente 7 de abril que tuvo lugar en la sinagoga de Arándiga, está fechada el 17 de noviembre de dicho año, en Épila. Este día Caçon volvió a actuar como testigo instrumental en la comanda de doscientos ochenta y ocho sueldos que los moros de Rueda Ali Zambriel, Ali de Abocach y Muça el Romo recibieron del judío epilense Hahim Sumiel, mayor ${ }^{463}$.

En cuanto a Jaco Eli, sólo nos consta que, el 17 de febrero de 1485, en Calatayud, el citado Alazar Serrano lo nombró su procurador, junto con sus convecinos Sento Arruet, menor, Jaco Carillo, menor, Sento Haçan, Jaco Alpullat y Salamon Serrano, para presentar su privilegio de franqueza ${ }^{464}$.

Fichel

Un único judío con este apellido residió en Arándiga: Saul, que asistió a la reunión de la aljama del 30 de enero de 1444 .

Saul mantuvo una estrecha e íntima relación con la conversa turolense Brianda Besante. Saul la servía y le guisaba el viernes para el sábado. Con frecuencia la conversa lo llamaba para que le dijera el «samá»; él se lo leía siempre en hebreo por lo que Brianda recibía «gran consolacion», sabiendo que hablaba de su «ley»y del Mesías anhelado. «Saul»-suspiraba Brian$\mathrm{da}-$, «quiera el Dio que veamos con bien este Mesias» ${ }^{465}$.

\footnotetext{
${ }^{463}$ Z.APN., Antón de Abiego, 1483, fol. 120v.

464 C.APN., Forcén López, 1485, fol. 26v.

465 A ello se refieren M. SÁnCHEZ MOYa y J. MONASTERIO ASPIRI, «Los judaizantes turolenses en el siglo XV», Sefarad 32 (1972) págs. 105-140 y 307-340, y 33 (1973) págs. 111-143 y 325-356: 32 pág. 334.
} 


\section{Frances}

Un único judío con este apellido residió en Arándiga en la primera mitad del siglo XV: Acach.

Las noticias que la documentación vista aporta sobre Acach Frances, se refieren a sus entregas en comanda a cristianos y judíos que habitaban en Épila. El 20 de enero de 1405, en dicha villa, Jaime de Abastado y su mujer María de Ainsa reconocieron que tenían que pagar a Acach ciento veinte sueldos, que «al conto e mandamiento del senyor Rey aquellos nos emprestasteis e al dito conto en poder nostro reciviemos»; sobre las ganancias y «misiones» que se produjeran, se creería la palabra de Acach ${ }^{466}$. El siguiente día 20 Sancho de Abastado y su mujer Toda Pérez de la Muela reconocieron que tenían que pagar a Acach doscientos cuarenta sueldos del modo dicho ${ }^{467}$. El 16 de abril de 1422, los judíos Abraham Gaddax, su mujer Ceti Çarfati y sus hijos Abi Gaddax, Ezdra Gaddax y el converso Pedro Gómez, vecinos de Épila, recibieron en comanda de Acach Frances cuatrocientos sueldos, que devolverían cuando este quisiera ${ }^{468}$; a continuación, el matrimonio y sus hijos judíos reconocieron que, aunque Pedro «fuese obligado aqueste dia mismo con ellos ensemble» en dicha comanda, «no avia preso de aquellos ningun dinero», por lo que prometieron «redrarle de todo danyo» ${ }^{469}$. Diez años después, el 2 de agosto de 1432, en Zaragoza, el noble don Juan Martínez de Luna, señor de Illueca, concedió la siguiente «licencia e permiso» a Acach Frances que «soliays estar e habitar en el lugar mio de Arandiga»:

466 Obligaron sus personas y bienes inmuebles; renunciaron a sus jueces, ordinario y local; harían cumplimiento ante el justicia de Aragón, etc. (siguen fórmulas jurídicas).

467 Obligaron sus personas y bienes inmuebles; se especificó además: «renunciamos encara a qualesquiere cartas de gracia, de alarga, de guiage et de sobreseymiento o longamiento e eviccion del senyor Rey, de la senyora Reyna, del senyor duch gobernador justicia de Aragon et de qualesquiere otros judges o senyores avientes poder de atorgarlas inpetradas et obtenidas impetraderas ...» (L.A.APN., Martín de Talamanca, 1405, fols. 6-17).

468 Obligaron sus personas y bienes inmuebles, especialmente sus casas del barrio del Burgo y su huerto con una tañería en la Puerta de la Peña; «prendieron quinyan los sobre ditos judios en poder de Acach Azarias, testimonio dius scripto»; nombraron procuradores para recibir sentencia condenatoria, en caso de litigio, a tres notarios cristianos de Zaragoza y al notario de Arándiga Martín Civera.

${ }^{469}$ L.A.APN., Remiro de Sádaba, 1422, fols. 36-37. 
que podaes estar e seyer vassallo del senyor Rey alla do a vos plazera e bien visto sera con vuestra familia e companya; prometo por aquesta razon nunqua fazervos contrast dius obligacion de todos nuestros bienes asi mobles como sedientes, havidos e por haver en todo lugar. E queremos, atorgamos e expressament consentimos que vos dito Acach Frances podades usar, estar e habitar, entrar e sallyr en nuestra tierra e lugares e demandar e recebir vuestros deudos, censsales e otros qualesquiere otros bienes, asi mobles como sedientes e regir e administrar aquellos. Et prometemos e convenimos e nos obligamos e encara en nuestra buena fe no fazer ni consentir vos seyer feyto mal, enoyo ni danyo ni razon en toda mi tierra e lugares por mi muxer, servidores ni vasallos directament ni indirecta por ningunas causas o razones feytas por vos dito Açach fines al present dia de guey. Encara prometo e me obligo de fazer e començar soltar vuestro yerno e filla los quales yo tiengo presos o restados en el dito mi lugar de Arandiga e fazer cancellar cierta obligacion que Juce Açan tiene sobre los ditos yerno e filla, etc., fiat large, etc. ${ }^{470}$.

¿Cuál pudo ser el motivo de que don Juan hiciera semejante favor a Acach Frances y obligara todos sus bienes a mantenerlo, le concediera libertad de hacerse vasallo real a la vez que le permitía entrar y salir de los lugares de su señorío para demandar y recibir sus deudos y censos, no consintiera que se le hiciera «mal, enoyo ni danyo» en toda su tierra, pese a tener presos en Arándiga a su hija y yerno, y se comprometiera a cancelar la obligación que estos tenían con el judío de Arándiga Juce Haçan? ¿La fortuna de Acach Frances era tan importante como para que su cambio de residencia pudiera suponer un perjuicio económico en Arándiga y, quizás, en todo el señorío de los Martínez de Luna, perjuicio que don Juan con dicho permiso pretendió evitar? Nada se puede afirmar con seguridad al respecto. Han de transcurrir más de catorce años, para que la documentación vista aluda de nuevo a Acach Frances, que pudo fallecer en 1440. El 5 de abril de 1446, en Calatayud, su hijo, heredero y sucesor Juce Frances, que vivía en La Almunia de Doña Godina, vendió al judío bilbilitano Abraham Paçagon los sesenta florines de oro que los vecinos de Munébrega Pedro de Villar, el notario Bartolomé Crespo,

${ }^{470}$ Z.APN., Antón Melero, 1432, fols. 26v-27. 
Juan Ximeno de Moros y Pedro Tello, debían a su padre en comanda ${ }^{471}$, por sesenta florines de precio ${ }^{472}$. En el siguiente mes de mayo se aludió por última vez a Acach Frances y a sus herederos ${ }^{473}$, sus hijos Jehuda y Juce. Ambos hermanos pidieron permiso a los adelantados y a la aljama de La Almunia de Doña Godina, en 1454, para irse a una judería de realengo, la de Calatayud; finalmente no cambiaron su residencia ${ }^{474}$.

${ }^{471}$ Hecha el 1 de febrero de 1440 , en Calatayud.

${ }_{472}$ Tomó «quinyan etc., fiat ... de la falda de Ceti Lapapa» (C.APN., Antón Martínez de la Justicia, 1446, fols. 110-110v).

${ }^{473} \mathrm{El}$ martes 24 de mayo de 1446, en Épila, «en las puertas, si quiere, habitacion» de María de la Muela, alias de la Nodriza, en presencia de Pedro Servando, lugarteniente del sobrejuntero mayor de la Junta de Tarazona, don Baldomero Cavero, del notario de dicho lugarteniente de sobrejuntero, Juan Montañés, del justicia Pedro de Falcés y de los presentes Antón Navarro y Antón de Ateca, compareció el epilense Juan Vidal y dijo las siguientes palabras, ante el notario y testigos: «Don Pero Servant, segunt que a mi noticia ys proveido que vos bos haveredes opposado sobre Pero Gomez, vezino qui ys aqui de la dita villa de Epila, diziendo e afirmando el seyer caplevador de una exsecucion que fue feyta a mi por Francisco d'Ovelsa, lugatenient del sobrejuntero, a instancia de Martin Perez d'Anbel, vezino del lugar de Arandiga, e como aquel deudo no obstant el contrato dizies a el aquel deudo el transporto en poder de don Acach Frances, judio de Arandiga e de Acach Frances ys proveido aquel deudo en poder de Juce Cariello, judio habitant en el lugar del Almunia, con el qual mediant buenhas personas intervenientes entre el e mi ys stado composado aqueste deudo por via de arbitracion mediant sciertas penas entre el e mi composadas de las quales quanto mester sera so presto e parellado fazerne pronpta fe, porque me maravello qui vos agora por virtut de ningun deudo qui yo al dito Martin Perez d'Anbel vos fagaredes crevanto contra el dito Pero Gomez, asi como a caplevador de la dita exsecucion, car vos saberedes bien que si por virtut del dito Martin Perez de Anbel vos me fazeredes ningun crevanto vos saberedes bien por mi vos fue presentada firma de dreyto del justicia de Aragon contra el, la qual encara no consta ni parece aquella seyerme repellida e si de part del dito Juce Carillo me fazeredes crevanto ninguno, me plaze bien saber de vos si asi ys por que por virtut de las penas del compromis entre mi e el conposadas yo lo pueda constituyr; por tanto vos requiero vos me digaredes a instancia de qui e por que vos vos averedes opposado sobre el dito Pero Gomez». La respuesta del lugarteniente del sobrejuntero a dicho requerimiento fue «qui el no demandava ninguna cosa al dito Johan Vidal ni al dito Pero Gomez por ninguna de las partes del dito Martin Perez de Anbel ni por el dito Juce Cariello, sino por parte de Acach Frances o de sus herederos a quien provenia aqueste deudo por demandacion fecha a el por el dito Martin Perez d'Anbel e que por aquellos demandavan la caplienda de la exsecucion fecha e acomendada al dito Pero Gomez e no por otri ninguno; de la qual relacion feita por el sobre dito lugarteniente del sobrejuntero, si quiere, de los XII sueldos quel dito Johan Vidal les die por salario de I dia quellos sieron en Epila sobre aquesta causa, requirio a mi notario lende fazies cartas publicas a conservacion de su dreyto» (L.A.APN., Martín de Marín, 1446, fols. 33-33v).

${ }^{474} \mathrm{~A}$ los dos hermanos y a sus descendientes me referí en MARín PADILLA «La Almunia» 51 págs. 51-77. 


\section{Franco}

Un único judío con este apellido residió en Arándiga: el albardero Daniel Franco. Vivió en unas casas de la villa que lindaban con dos portales contiguos, que el pelaire judío de La Almunia de Doña Godina Mosse Arruet tenía en Arándiga y que vendió al labrador vecino de esta villa Miguel Giral ${ }^{475}$. Son sólo dos las noticias documentales que a él aluden: el 3 de marzo de 1490, en Épila, el albardero Daniel recibió en comanda del escudero epilense Sancho Siscar treinta y cinco sueldos, de los que respondió con «hun asno de pelo pardo vel quasi» ${ }^{476}$; y el 24 de noviembre del siguiente año, también allí, Daniel actuó como testigo instrumental en un poder que el mercader judío de Zaragoza Adret Aninay dio a su convecino y hermano Astruch Aninay ${ }^{477}$.

\section{Funes}

Sólo un judío con este apellido residió en Arándiga: Mosse. De él sólo nos consta que actuó como testigo instrumental, el 11 de julio de 1446 , en Calatayud ${ }^{478}$, además de recibir en comanda, junto con su convecino Salamon Haym y el albardero bilbilitano Simuel de Funes, trescientos treinta sueldos del mercader converso de Calatayud Juan Daza ${ }^{479}$.

\section{Granadino}

Un único judío apodado el Granadino residió en Arándiga: Acach. Por su oficio de «erbolero»o «fetillero» Acach el Granadino tuvo que hacer viajes fuera de Arándiga; en 1488 estuvo en Ricla dos meses haciendo «curas». Fue entonces cuando, ocho días antes del Kipur, le preguntó el agricultor converso Jaime de Urgel que cuándo era el ayuno. «Tal día», le dijo Acach. Dos o tres días antes, Acach tuvo que irse de Ricla y le preguntó Jaime que a dónde iba. Cuando le dijo que

${ }^{475}$ L.A.APN., Miguel Contín, 1491, fol. 98v.

${ }_{476}$ Juró no pleitear (Z.APN., Antón de Abiego, 1490, fol. 30v).

477 L.A.APN., Martín Ramo, 1491, fol. 114v.

478 C.APN., Antón Martínez de la Justicia, 1446, fol. 180v.

479 C.APN., Leonardo de Santa Fe, 1465, fols. 55-56; donde se alude a dicha carta de comanda. El resumen del proceso inquisitorial del converso Juan Daza puede consultarse en MARín PADILla Contribución vol. III págs. 803-809. 
a La Almunia de Doña Godina, le pidió que le trajera una libra de carne de la carnicería de los judíos de esa villa y le dio un sueldo. Una libra de pierna de carnero le trajo Acach; al cogerla Juan empezó a «purgar del nervio o glandolica» y, después de decirle que sabía hacerlo, le comentó que el día del Kipur tenía que ayunar. En el mes de abril de ese año, los inquisidores, después de tomar declaración a testigos de acusación de conversos judaizantes de Calatayud y lugares de alrededor, partieron a Zaragoza. El converso dijo a Acach en secreto que tenía miedo de que lo apresaran, y que, si quería ir con él y «demostrarle los pasos para pasarse a Berberia», le daría una mula y lo "satisfaria bien». Acach se negó a hacerlo alegando que el tiempo era peligroso y que por nada de este mundo dejaría a su mujer; Jaime calló y no dijo nada más. Pasó un año y a finales de mayo de 1489 , el converso lo mandó llamar a Arándiga, a través de Pedro Magallón, de la mujer del molinero de esa villa Antón Ferrández y de Juan, el hijo del vicario de Ricla, pero Acach se negó a ir a esta villa ${ }^{480}$. Finalmente, el converso fue apresado por el tribunal del Santo Oficio, tal como sospechaba. En la confesión que hizo ante él admitió que, a causa del miedo que tenía a que lo detuvieran los inquisidores, había comentado ante Juan de la Sanz, Juan Ortiz, el vicario de Ricla mosén Dionis y el citado Acach, que estaba a punto de pasarse a Judea y hacerse judío, visto como iban las cosas y de la forma que los trataban. A lo que el vicario añadió que «no estaban sino por robar y que eran robadores» ${ }^{481}$.

\section{Haçan (Azan y Hazan)}

Dos judíos con este apellido residieron en Arándiga: Juce y Sento.

Fue Juce Haçan uno de los judíos en quien depositaron su confianza los señores de Illueca y Arándiga ${ }^{482}$. Vasallo de don Juan Martínez de Luna -quien se obligó en 1432 a cancelar la

${ }^{480}$ Z.AAT, legajo nuevo $n^{\circ} 3$, encontrado después de la catalogación, fols. 7-8: testificación de Acach, el 6 de junio de 1489 .

${ }^{481}$ Dicho legajo y número, fol. 19: confesión de Jaime, el 29 de abril de 1490 , en Zaragoza.

482 También don Lope Ximénez de Urrea, señor de Épila, nombró receptor de sus rentas en la villa a un judío, Jaco Fichel, en 1427. 
deuda contraída con Juce Haçan de la hija y el yerno de Acach Frances-, Juce había cobrado, regido, administrado, recibido e «bistraydo, si quiere», en nombre y por orden de don Juan, las rentas de sus lugares de Arándiga y Chodes en los años 1432 y 1433. El 31 de enero de 1434, en Zaragoza, don Juan Martínez de Luna, como su vasallo y vecino de Arándiga Juce Haçan le había dado buena cuenta de todo, lo absolvió, «quito y relexo» ${ }^{483}$. La relación con don Juan debió de ser la causa de que se entregara también a Juce una administración que, indirectamente, iba a afectar al señor de Illueca y Arándiga. Fray Gil Martínez, de la Orden del Hospital de San Juan de Jerusalem, comisario regidor y administrador de las casas y comandas de Zaragoza de dicha orden, encargó a Juce Haçan que, por él y en su nombre, demandara, cobrara y recibiera las rentas, derechos y emolumentos de La Almunia de Doña Godina y Cabañas - lugares e miembros» de dicha comanda-, en los años 1434,1435 y 1436 . El 10 de diciembre de 1437, en Zaragoza, fray Gil absolvió, «quito y difinio» a Juce: porque demandó, cobró y recibió dichas rentas, derechos y emolumentos; porque, por orden suya, las dio, libró y restituyó al noble señor de Illueca don Juan Martínez de Luna, «para sustenimiento de la persona» de su hermano el noble don fray Alvaro de Luna, comendador de dicha comanda y bailía de Zaragoza ${ }^{484}$; y porque de dichas rentas, derechos y emolumentos le dio «buen conto» ${ }^{485}$. Un año antes de que fray Gil aceptara las cuentas

${ }^{483}$ Siguen fórmulas jurídicas (Z.APN., Antón Melero, 1434, fols. 43-44).

${ }^{484}$ Según en carta de comisión, regimiento y administración «es contenido e me es mandado».

${ }^{485}$ El documento es muy extenso (Z.APN., Antón Melero, 1437, fols. 2-3v). Años después, en 1457, el notario Martín de Osoha y el «sonador» Alfonso de Gracia, vecinos de Zaragoza, emitieron sentencia, como árbitros y amigables componedores en el pleito que sostenían el noble señor fray Álvaro de Luna, caballero de la orden de San Juan de Jerusalem, y María Sánchez de Mayoral, viuda de Gil de Luna, en torno a la comanda de doscientos florines de oro que el noble recibió en 1445 de la zaragozana Beatriz de Luna, que prometió devolver sin dilación alguna y que, en 1457, pertenecían a dicha María. Cuando el notario Juan de Aguas compareció ante fray Álvaro de Luna para intimarle dicha sentencia le dijo: «Senyor, yo vengo aqui a vos por intimarvos una sentencia de compromis dada por los ... arbitros, arbitradores e amigables conponedores entre vos senyor de la una part demandant e defendient e Maria Sanchez de Mayoral ... de la part otra demandant e defendient, assi placia vos oyrla». "Fazet venir a favlar con mi a los arbitros ante que me la intimez», le contestó el fraile. «Senyor, no quieren venir ni vendran ante mandan intimarvosla, oytla", dijo el notario. "Pues aqui no me la intimez, venit a mi cassa", 
que le dio Juce y estuviera conforme con ellas, este actuaba en La Almunia de Doña Godina como «procurador del senyor». El 15 de octubre de 1436, en presencia del notario y testigos, compareció Antón Trigo, como procurador del judío de Zaragoza Abraham Gotina, ante el alcaide de la villa Lope del Molino, y le dijo:

Alcayde, a mi es dado a entender que vos haveys vendido por los trehudos un guerto del dito mi principal, el qual era de Loys de Funes et tenia agora Pedro de Anyon, me aposso en la vendicion assi mismo en los ditos cient et cinquanta solidos, que salvo quede el dreyto del dito mi principal como aquesto sia a conoxer al justicia de Aragon, a mayor complimiento el dito mi principal si en res es tenido de satisfacer toda cosa que sera trobado por verdat.

El alcaide le contestó «quel por mandamiento de Juce Azan, assi como procurador del senyor, havia vendido el dito guerto para los criados e que no se parte en su vendicion» ${ }^{486}$. Además de la responsabilidad que suponían estas administraciones, Juce Haçan se encargó de hacer determinados pagos debidos por lugares de los señores Martínez de Luna y Ximénez de Urrea. El 10 de enero de 1441, en Zaragoza, el mercader de la ciudad Gaspar Roiz recibió de las universidades de Illueca, Morata y Gotor, a través de Juce Haçan, cuatrocientos sueldos censales del censo anual y perpetuo que tenían que pagar cada 1 de abril, correspondientes a dicho día del pasado año ${ }^{487}$. Tres años después, el 30 de enero de 1444 , Juce asistió como adelantado a la reunión de la aljama, efectuada con motivo de los dos censos que se vendieron a don Golzalvo de la Caballería.

La documentación vista aporta bastantes noticias sobre otra actividad de Juce Haçan; la entrega de dinero en comandas en los años que median desde 1425 , con domicilio fijo en

\footnotetext{
insistió el noble. «Senyor, a cassa no yria, veyet si la querez oyr, sino fazerne carta publica pues mes mandada intimar o dezit que no la querez oyr», contestó el notario. "Guardat, no me la intimez sino yo scastigare e si no fuessemos endo somos yo scastiguaria faziendo. Remango del un tocho que tenia por darme e gira las cuestas e vage. E yo a scargo de mi oficio de todas e cada unas cosas sobreditas fize e testifique carta publica, etc. en testimonio de verdat, etc.» (Z.APN., Juan de Aguas, 1457, fols. 59v-60).

${ }^{486}$ L.A.APN., Pascual Contín, 1436, fol. 42.

${ }^{487}$ Z.APN., Pedro Sánchez de Calatayud, 1441, fol. 10.
} 
Arándiga, hasta 1450 , cuando cambió su residencia temporal a Almonacid de la Sierra para quedarse allí definitivamente. Aunque en alguna ocasión Juce fue deudor: el 23 de agosto de 1425 , en Arándiga y junto con otros judíos de la villa ${ }^{488}$ recibió en comanda cuatrocientos florines de oro del zaragozano Simón de Septiembre, mayor ${ }^{489}$; la mayoría de las veces fue él quien entregó comandas a cristianos y moros, algunas de las cuales vendió con posterioridad, o compró contratos debidos a otras personas. Los deudores de Juce Haçan procedían de La Almunia de Doña Godina ${ }^{490}$, de Alpartir ${ }^{491}$,

${ }^{488}$ Acach y Juce Carillo, hijos de don Jehuda Carillo, y Nahamias Zecri.

489 El 6 de julio de 1450, en Zaragoza, Simón de Septiembre, hijo y heredero de Simón de Septiembre -murió intestado-, recibió de Juce Carillo-entonces vivía en La Almunia de Doña Godina- cien de los cuatrocientos florines que dichos judíos debían desde hacía veinticinco años (Z.APN., Pedro Sánchez de Calatayud, 1450 , fols. $31 \mathrm{v}-34$ ).

${ }^{490}$ El 23 de diciembre de 1433, Juce dio en comanda al matrimonio Bartolomé Antolino y su mujer Sancha Pérez seiscientos sueldos. El 4 de septiembre de 1436, Domingo Guisabel y su mujer Inés de Jaca recibieron en comanda de Juce once florines de oro, de los que respondieron con una vaca y un buey. El 9 de febrero de 1441, el vecino de La Almunia de Doña Godina Lorenzo Just y el de Alpartir Jaime Añón recibieron en comanda de Juce cuatrocientos veinte sueldos. El 20 de agosto de 1444, en Almonacid de la Sierra, Juce vendió dicha comanda a Jehuda Frances; a éste se la pagaron los deudores el 31 de diciembre de 1452 (L.A.APN., Pascual Contín, 1436, fol. 26; 1451, fol. 8; y 1453, fol. 2; donde se alude a ello).

${ }^{491}$ El 22 de enero de 1438, en Arándiga, los vecinos de Alpartir Juan de Pallá y Domingo Capellán recibieron en comanda de Juce cuatrocientos sueldos. El 6 de junio de 1451, en La Almunia de Doña Godina, Juce vendió al labrador de Alpartir Domingo de Pola dicho contrato de comanda, «sano, salvo», por la misma cantidad. El 11 de septiembre de 1453, en dicha villa, Domingo volvió a vender el contrato por cuatrocientos sueldos de precio (L.A.APN., Pascual Contín, 1451, fol. $68 \mathrm{v}$; y 1453 , fol. 84 ). El 30 de noviembre de 1444, en La Almunia de Doña Godina, Jehuda Frances recibió del matrimonio de Alpartir Domingo Gastón y su mujer Sancha Calvo los seiscientos sueldos que debían a Juce -según comanda hecha el 27 de enero de 1439, en Alpartir-, comanda que él compró a Juce (dicho notario, 1444, fol. 91). El 16 de enero de 1454, en Alpartir y ante notario y testigos, comparecieron el vecino de allí Juan Pascual, menor, y Juce Haçan para aclarar: que Juan Pascual, mayor, padre de dicho Juan, sólo debía a Juce trescientos veinte sueldos que el hijo prometió pagar hasta el siguiente día de San Juan Bautista; y que, una vez efectuado el pago, Juce le vendería cualquier contrato que tuviera en su poder, especialmente el de doscientos sesenta sueldos que su padre debía -según comanda hecha el 13 de agosto de 1444, en La Almunia de Doña Godina-; el de ciento cuarenta sueldos que su padre debía -según comanda hecha el 26 de mayo de 1439 , en Alpartir-; y el de ochenta sueldos que el hijo debía -según comanda hecha el 7 de marzo de 1446, en Cosuenda. Ambas partes prometieron cumplir lo pactado y obligaron sus personas y bienes a hacerlo. El siguiente 4 de julio en 
de Calatayud ${ }^{492}$, de Chodes ${ }^{493}$, de Épila ${ }^{494}$, de El Frasno ${ }^{495}$, de Lumpiaque ${ }^{496}$, de Nuella ${ }^{497}$ y de Ricla ${ }^{498}$.

dicho lugar, Juce vendió a Juan Pascual, menor, los tres contratos de comandas, «sanos, salvos», por quinientos veinte sueldos de precio (dicho notario, 1454, fols. $8 v-9$ y $43 v$ ).

${ }^{492}$ El 18 de septiembre de 1444, en Almonacid de la Sierra, Jehuda Frances compró a Juce Haçan: los mil sueldos que debían los mercaderes bilbilitanos, los hermanos Lázaro y Jaime Álvarez, menor, y que Juce compró el 23 de octubre de 1442, en Calatayud, a Pedro de Almazán, hijo y heredero del notario bilbilitano Pascual Pérez de Almazán, a quien se le debían en contrato hecho el 1 de mayo de 1433, en dicha ciudad; y los ciento diez florines que quedaban por cobrar de los mercaderes bilbilitanos, el citado Jaime Álvarez, menor, y Pedro de Valtueña. Estos debían doscientos diez florines al bachiller en medicina Berenguer de la Cabra, menor -según comanda hecha el 18 de mayo de 1439, en dicha ciudad. Luego, el ciudadano Miguel Pérez de Calatayud y el escudero Pedro de la Cabra, como tutores y curadores de las personas y bienes de Juan, Leonardo y María de la Cabra, hijos de Berenguer, vendieron a Juce ciento diez florines de los doscientos diez que se debían -según venta hecha el 3 de octubre de 1442, en dicha ciudad. Estos contratos, «sanos, salvos», los vendió Juce a Jehuda «por lo mismo que montan», que recibió con el alifara. Juce se obligó a evicción, respondió con sus bienes y «presso quinyan en poder» del judío de Almonacid Nahamen Abencanyas (L.A.APN., Pascual Contín, 1444, fols. 66v-67).

${ }^{493}$ El 17 de junio de 1443, en dicho lugar, los moros «Yuce el Minchen mayor de dias, Yuce Cayt, Mingen Dorramon el ferrero, Ali el Mingen alfaqui, Mahoma el Mingen, Yuce el Tardano, Mahoma el Mingen, Avdalla el Donyoro, Mahoma Luzena, Yuce el Mingen menor de dias, Mahoma el Tardano, Brahem Donalia, Calema el Mingen, Brahem el Pardo, Gualit de Moferriz et Mahoma Cayt» y Juce Haçan recibieron del citado Juce Frances una comanda. El 18 de septiembre de 1444, en Almonacid de la Sierra, el judío del lugar Salamon Cohen compró a Juce Frances el contrato de comanda en el que Juce Haçan y los moros de Chodes le estaban obligados; los trescientos cincuenta sueldos de precio los recibió con el alifara; en caso de pleito le vendería otro contrato de igual valía; obligó su persona y bienes (L.A.APN., Pascual Contín, 1444, fols. 65-65v).

${ }^{494}$ El 30 de septiembre de 1444, en Almonacid de la Sierra, Juce que se encontraba allí «de present», recibió de los moros de Épila Brahem Canzalla, su mujer Cora la Guaxqui, Yuce el Pastor y su mujer Marien de Canzalla, los doscientos sueldos que le debían -según comanda hecha el 31 de diciembre de 1433, en Épila (L.A.APN., Pascual Contín, 1444, fol. 71v).

495 El 18 de septiembre de 1444 , en Almonacid de la Sierra, Jehuda Frances compró a Juce Haçan los cuatrocientos sueldos que debían los vecinos de El Frasno Martín Rasera, su mujer Sancha y Juan de la Villa -según contrato hecho el 14 de septiembre de 1436, en este lugar (L.A.APN., Pascual Contín, 1444 , fol. $66 \mathrm{v}$ ).

${ }^{496}$ El 30 de septiembre de 1444, en Almonacid de la Sierra, Juce Haçan que se encontraba allí «de present», vendió al judío de Zaragoza Juce Abiayu los doscientos sueldos que el matrimonio moro de Lumpiaque Brahem Carich y su mujer Marien de Pariant le debían -según comanda hecha el 29 de noviembre de 1437, en Épila-, por la misma cantidad de precio (L.A.APN., Pascual 
La relación de Juce Haçan con los hermanos judíos Juce y Jehuda Frances pudo motivar que al pleitear ambos -como herederos de los bienes de su difunto padre don Jehuda Frances ${ }^{499}$, con la viuda doña Urraca Díaz del Trigo -como «tenedora de los bienes» de su difunto marido mosén don Luis- lo nombraran árbitro, cuando él estaba en Almonacid de la Sierra, junto con Jaime de Mozos, vecino de La Almunia de Doña

Contín, 1444, fol. 70v). El 16 de julio de 1450, en Almonacid de la Sierra donde residía, Juce Haçan vendió al trapero de Zaragoza Juce Abiayu los doscientos sueldos que los moros de Lumpiaque Brahem de Castiello y Farax de Rabadan le debían -según comanda hecha el 11 de octubre de 1434, en Épila-, por la misma cantidad de precio (Z.APN., Pedro Sánchez de Calatayud, 1450, fols. 9v$10)$.

${ }^{497}$ El 18 de septiembre de 1444, en Almonacid de la Sierra, Juce Haçan, que «de present» se encontraba allí, vendió a Jehuda Frances un contrato de mil sueldos que los moros vecinos de Nuella «Ali Jamilla alamin, Dorramen de Zara jurado, Yuce Jamilla menor de dias, Mahoma el Alffaqui, Ali de Zara, Mahoma Laxarich, fillo de Juce Laxarich, Mahoma Jamilla mayor de dias, Dorramen del Alamin, Yuce el Pastor, Yuce la Plaza, Yuce el Calvo, mayor de dias, Yuce Jamilla mayor de dias, Mahoma Girruan [?], Dorramen de Ayho, Ali de Zara menor de dias, Brahem Canzala, Yuce de Muça, Brahem Ayze, Mahoma Lazarich, Mahoma Lazarich, fillo de Dorramen Lazarich et Mahoma el Pastor», vasallos de don Lope Ximénez de Urrea, le debían -según contrato hecho el 27 de marzo de 1444, en Nuella. El siguiente 21 de septiembre en La Almunia de Doña Godina, Jehuda Frances vendió a su hermano Juce Frances los mil sueldos de dicho contrato, por la misma cantidad. También el 18 de septiembre de 1444, en Almonacid de la Sierra, Juce Haçan vendió a Jehuda Frances una carta de deudo de quinientos nueve sueldos, en la que el moro de Nuella Dorramen de Jamilla le estaba obligado -según carta hecha el 22 de abril de 1443, en Arándiga-; recibió con el alifara los mil quinientos nueve sueldos del precio de ambas ventas (L.A.APN., Pascual Contín, 1444, fols. 65v66 y $67 \mathrm{v}-68)$.

498 El 30 de septiembre de 1444, en Almonacid de la Sierra, Juce Haçan, que se encontraba allí «de present», vendió al notario de Villafeliche Juan Ximeno los veinte florines de oro que los moros de Ricla Zara Alhazan y su hijo Mahoma el Pastor le debían -según comanda hecha el 1 de enero de 1440, en Ricla-, por la misma cantidad de precio que recibió con el alifara. A continuación, aunque Zara y su hijo debían a Juce muchas y diversas cuantías de dineros, florines, panes, vino, olio y otros bienes y mercaderías, como habían llegado a «buen conto», Juce se consideró pagado y otorgó defenecimiento. También el 30 de septiembre en el mismo lugar, Juce llegó a «buen conto» con el labrador de Ricla Domingo de Soria que le debía diversas cuantías de dineros, florines y otras cosas, pero le quedaban por pagar treinta cahíces de trigo, en cinco años, que entregaría a Jehuda Frances; una vez pagados, Juce le daría una carta de quinientos sueldos y le haría albarán «e difinimiento»; ambos juraron, según su ley, el labrador pagar a Jehuda, bajo pena de perjuro, y Juce cumplir lo acordado (L.A.APN., Pascual Contín, 1444, fols. 70v-72).

${ }^{499}$ Según se ha visto al referirme al apellido Frances, creo que el padre de los hermanos Juce y Jehuda no era Jehuda, sino Acach Frances. 
Godina, como los contrincantes. El nombramiento se hizo en esta villa el 27 de octubre de 1444; el plazo para emitir sentencia, que se aceptaría bajo pena de quinientos florines, fue el siguiente mes de noviembre; dicha pena, que pagaría quien no cumpliera la sentencia tantas veces como lo hiciera, se dividiría en tres partes iguales, una para el rey, otra para los árbitros y la tercera para la parte obediente ${ }^{500}$. El 27 de noviembre, en Almonacid de la Sierra, los árbitros prorrogaron el tiempo de emitir sentencia hasta diciembre. El día 23 de ese mes en dicho lugar, Jaime de Mozos y Juce Haçan, árbitros entre la viuda doña Urraca y los hermanos Frances, emitieron sentencia, después de hacer constar que habían visto, oído y entendido los pleitos y cuestiones existentes entre ambas partes, y que se daban de tiempo el siguiente mes de enero para corregirla y enmendarla. En dicha sentencia los árbitros mandaron, bajo las penas contenidas en el compromiso: que doña Urraca pagara a los hermanos Frances veinticinco florines de oro en el plazo de un año, a partir de que se le intimara la sentencia; que, una vez pagados, ambas partes se hicieran defenecimiento general y mutuo de todas las demandas y cuestiones que tuvieran hasta entonces; que pagaran a los árbitros, por sus trabajos, sendos pares de guantes, doña Urraca a Jaime y los Frances a Juce, en el siguiente mes de enero; y que cada parte pagara al notario, por recibir la sentencia, el compromiso y otros afanes, dos florines en el siguiente mes de enero. El día 24 de diciembre el notario intimó la sentencia a doña Urraca y a los Frances, que aceptaron su contenido ${ }^{501}$.

La solvencia económica y el prestigio de Juce Haçan pudieron motivar que el judío de Zaragoza Nahamen Bivag lo nombrara, junto con su mujer Jamila de Arsan y el judío zaragozano Simuel Camph, alias Trigo, tutor y curador de las personas y bienes de sus hijos Sento, Bellita y Orico Bivag, cuando hizo testamento en $1442{ }^{502}$.

\footnotetext{
500 Ambas partes obligaron sus personas y bienes, muebles e inmuebles.

501 L.A.APN., Pascual Contín, 1444, fols. 80v-81, 90 y 99-101v.

502 El 19 de enero de 1447, en Épila, el judío zaragozano Nahamen Gotina, como procurador de dicho tutor y curador Juce Haçan -según poder hecho el 22 de julio de 1443, en Arándiga-, recibió del matrimonio epilense Bernardo Alger y su mujer María Marín los ciento cincuenta sueldos y un cahíz y medio de trigo que debían a Nahamen Bivag en comanda, hecha el 4 de septiembre de 1438, en Épila (L.A.APN., Martín de Marín, 1447, fols. 16-16v).
} 
Años después, cuando residía en Almonacid de la Sierra, Juce Haçan era procurador de Gracia Pérez de Ambel, hija legítima y heredera universal de los bienes, muebles e inmuebles, de su padre Martín Pérez de Ambel, vecino de Arándiga. El 22 de junio de 1451, en La Almunia de Doña Godina y como tal procurador ${ }^{503}$, Juce recibió seiscientos sueldos que los vecinos de Alpartir Domingo Ibáñez y su mujer Antona Ferrer, y el vecino de La Almunia Pedro Salillas, debían a Martín 504; luego los absolvió y dejó libres de la deuda ${ }^{505}$.

Los frecuentes viajes de Juce Haçan y sus distintas residencias fueron causa de sus comparecencias como testigo instrumental en diferentes lugares. El 4 de mayo de 1440, en La Almunia de Doña Godina, Juce actuó como testigo instrumental de la venta de una viña y un huerto que los citados hermanos judíos Jehuda y Juce Frances vendieron al vecino de Arándiga Antón Doncellón, por trescientos sueldos de precio; y de la comanda de seiscientos que a éste le dio dicho Jehuda ${ }^{506}$. El siguiente 19 de agosto en Alpartir, Juce volvió a actuar como testigo instrumental en la comanda de seiscientos sueldos que un matrimonio cristiano del lugar recibió del judío de Arándiga Juce Biel ${ }^{507}$. Los días 10 y 11 de agosto de 1444 , de nuevo en La Almunia de Doña Godina, Juce Haçan actuó como testigo instrumental en dos comandas que dio el citado Jehuda Frances: una, al vecino de Arándiga Domingo Lázaro, el Joven, de cinco florines de oro; y otra, de cuarenta florines de oro a dos cristianos de Calatayud y El Frasno 508 . El 22 de junio de 1451, en La Almunia de Doña Godina, Juce Haçan fue testigo instrumental en el contrato de comanda de quinientos sueldos que los vecinos de El Frasno Gil Álvaro y su mujer Antona Ferrer recibieron del mismo Jehuda Frances ${ }^{509}$.

\footnotetext{
503 Según poder hecho el 23 de marzo de 1432, en Arándiga.

504 Según comanda hecha el 4 de marzo de 1417, en La Almunia de Doña Godina.

${ }^{505}$ L.A.APN., Pascual Contín, 1451, fol. 75.

506 De los que respondió Antón con la viña y huerto comprados y con sus casas de Arándiga, que lindaban con las de Antón de Aranda, con las de Teresa Navarro y con carrera pública.

507 L.A.APN., Pascual Contín, 1440, fols. $29-29$ v y 59.

${ }^{508}$ Dicho notario, 1444 , fols. $48 \mathrm{v}$ y $50 \mathrm{v}$.

509 Dicho riotario, 1451, fol. $74 \mathrm{v}$.
} 
Dejemos a Juce Haçan residiendo en Almonacid de la Sierra en julio de 1454, junto con su hijo Alazar, que también desde hacía años entregaba préstamos y comandas ${ }^{510}$.

Por lo que se refiere a Sento Haçan, sólo nos consta que Alazar Serrano lo nombró procurador, junto con otros judíos, el 17 de febrero de 1485 , como se ha visto.

[Continuará]

${ }^{510}$ El 17 de junio de 1451, en La Almunia de Doña Godina, Alazar dio en comanda a los vecinos de Alpartir Juan Pascual, alias Colniello, y a su mujer Sancha López ciento cuarenta sueldos (dicho notario y año, fol. 73v). 